\title{
Adsorption of Methylene Blue on the Composite Sorbent Based on Bentonite-Like Clay and Hydroxyapatite
}

\author{
Alexandr Ivanovich Vezentsev ${ }^{1}$, Dang Minh Thuy ${ }^{1,2, *}$, \\ Lidia Fedotovna Goldovskaya-Peristaya', and Nadezhda Alexandrovna Glukhareva' ${ }^{1}$ \\ ${ }^{1}$ Belgorod State National Research University, 85 Pobedy St., Belgorod 308015, Russia \\ ${ }^{2}$ Russian-Vietnamese Tropical Center, 44 Nguyen Van Huyen St., Cau Giay, Hanoi, Vietnam
}

Received July 16, 2018; Accepted September 25, 2018

\begin{abstract}
The adsorption of methylene blue from model aqueous solutions on bentonite-like clay, hydroxyapatite, and a composite sorbent has been investigated. The kinetic and thermodynamic parameters of adsorption in the temperature range 298-333 $K$ have been calculated. The process is found to obey Langmuir isotherm equation. It is spontaneous but slightly endothermic. The maximal sorption capacity of the composite sorbent toward methylene blue is $175.4 \mathrm{mg} / \mathrm{g}$ at $25^{\circ} \mathrm{C}$ that is 1.3 times higher than that for bentonite-like clay and 17.8 times hgiher than that for hydroxyapatite. Kinetics of the process is due to the combination of external and internal diffusion and can be described better by the model of pseudo-second order reaction.
\end{abstract}

Keywords: adsorption; thermodynamics; methylene blue; composite sorbent

\section{ABSTRAK}

Telah dilakukan penelitian mengenai adsorpsi metilen biru dari model larutan berair pada lempung bentonit, hidroksiapatit, dan komposit sorben. Parameter kinetik dan termodinamik dari adsorpsi pada rentang suhu 298-333 $\mathrm{K}$ telah dihitung. Dari perhitungan didapatkan bahwa proses adsorpsi mengikuti persamaan isoterm Langmuir yang bersifat spontan tetapi sedikit endotermik. Kapasitas penyerapan maksimum metilen biru menggunakan komposit sorben adalah 175,4 mg/g pada $25^{\circ} \mathrm{C}$. Kapasitas penyerapan maksimum ini 1,3 kali lebih tinggi dibanding adsorpsi dengan lempung bentonit dan 17,8 kali lebih tinggi dibanding menggunakan hidroksiapatit. Kinetika proses ini disebabkan oleh kombinasi difusi eksternal dan internal dan dapat digambarkan dengan lebih baik menggunakan model kinetika reaksi pseudo orde dua.

Kata Kunci: adsorpsi, termodinamik; metilen biru; sorben komposit

\section{INTRODUCTION}

Dyes have been known to be important raw materials in textile, polygraphic industry, and other related branches. The discharge of wastes containing organic dyes into natural water sources results in the decrease in dissolved oxygen concentration. It prevents light penetration and inhibits photosynthesis in plants. Many organic dyes are harmful to human beings and toxic to microorganisms. Besides, they can form coordination compounds with some poisonous metal ions.

Methylene blue (MB) is used as a disinfectant in medicine, in pharmaceutical formulations, in pesticides production, varnish and lacquer manufacturing, among others [1]. Cationic dyes such as MB are reported to be more toxic than anionic ones [2]. MB irritates human skin, eyes, and can even have a carcinogenic effect [3-4]. That is why the removal of $\mathrm{MB}$ and other dyes from wastewater is a serious ecological problem all over the world.

* Corresponding author. Tel : +7-952-438-86-25

Email address : thuybsu@gmail.com
There are some ways to remove organic dyes, namely biodegradation [5], coagulation [6], oxidative catalytic degradation [7], membrane technologies [8], electrochemical degradation [9], adsorption [10]. However many organic dyes are resistant to sunlight, temperature effect, and many chemical reagents because of their complicated aromatic molecular structures, so they are difficult to remove from water by usual chemical methods [11-12]. On the contrary, the adsorption technique is one of the most popular methods of organic dyes removal because it is easy and highly efficient.

Nowadays search of inexpensive and readily available adsorbents brings scientists to find the more efficient use of natural, artificial, and synthetic materials as sorbents [13-14]. Clay minerals are the most widespread among natural minerals applied as adsorbents. Clay minerals of structural type 2:1 with changing basal spacing (montmorillonites) are known to

DOI: $10.22146 /$ ijc. 37050

Alexandr Ivanovich Vezentsev et al. 
Table 1. Some colloidal properties of the adsorbents

\begin{tabular}{lccc}
\hline \multicolumn{1}{c}{ Parameters } & \multicolumn{3}{c}{ Adsorbents } \\
\cline { 2 - 4 } Zeta-potential of particles in water at $\mathrm{pH}=7, \mathrm{mV}$ & -25 & $\mathrm{HA}$ & $\mathrm{C}-\mathrm{HA}$ \\
Specific surface area, $\mathrm{m}^{2} / \mathrm{g}$ & 52.11 & +2 & -22 \\
$\mathrm{pH}_{\text {pzc. }}$ (zero point of charge) & 5.7 & 85.78 & 96.81 \\
\hline
\end{tabular}

be effective. Molecules of water and organic substances as well as positively or negatively charged ions can be included in the inter-package cavities of the minerals. Ion exchange with the ions from the surroundings can take place in them. The clay minerals concerned can swell because of increase of space between basal layers where absorbed ions or molecules are located [15].

The application of apatite materials for adsorption and immobilization of various pollutants is a promising technique because of their high absorptivity, ease of use and environmental friendliness [16]. Hydroxyapatite (HA) $\mathrm{Ca}_{10}\left(\mathrm{PO}_{4}\right)_{6}(\mathrm{OH})_{2}$ has been known as the main inorganic constituent of bones and teeth of mammals and the component of phosphate mineral rocks [17]. HA has been used for the removal of toxic heavy metal ions, dyes, fluoride ions from aqueous solutions [18-22]. However, to separate suspended highly dispersed solid particles of HA from the aqueous solutions after adsorption is quite difficult [19-23]. Positive results of the application of composite materials based on HA for water purification are known.

The aim of the work is the investigation of methylene blue sorption on bentonite-like clay, hydroxyapatite, and the composite sorbent based on bentonite-like clay and hydroxyapatite (C-HA) prepared by the chemical precipitation.

\section{EXPERIMENTAL SECTION}

\section{Materials}

Three materials were used as sorbents, namely bentonite-like clay (BT6) from Tam Bo deposited (Lam Dong Province, Vietnam), hydroxyapatite (HA), and the composite sorbent (C-HA) prepared by the method described earlier [24].

Hydroxyapatite synthesis: HA was synthesized by adding a $10 \%$ (mass) solution of orthophosphoric acid to $\mathrm{Ca}(\mathrm{OH})_{2}$ solution with the rate $1.5-2.2 \mathrm{~mL} / \mathrm{min}$ per liter of the saturated solution of calcium hydroxide. The reaction mixture was stirred for 20-30 minutes with the stirring (1000 rpm) till the $\mathrm{pH}$ of the mixture achieved $10.5 \pm 0.5$, then the mixture was allowed to settle for $24 \mathrm{~h}$. The product obtained was separated from the mother liquor by filtration, rinsed with distilled water and then dried in a baker at $105 \pm 5^{\circ} \mathrm{C}$ for $5 \mathrm{~h}$. The samples were powdered in a porcelain mortar.
The preparation of the composite sorbent $(\mathrm{C}-\mathrm{HA})$ : A $5 \mathrm{~g}$ sample of bentonite-like clay was added to a $5 \mathrm{~L}$ vessel containing $1880 \mathrm{~mL}$ of the saturated solution of $\mathrm{Ca}(\mathrm{OH})_{2}$. The suspension was stirred with the stirring shaft mentioned above for $2 \mathrm{~h}$. The required volume of a $10 \%$ solution of orthophosphoric acid was added with the rate of $1 \mathrm{~mL} / \mathrm{min}$ at intensive stirring $(1000 \mathrm{rpm})$ to provide the mole relation $\mathrm{Ca}: \mathrm{P}$ equal to 1.67 . Then the solution was stirred for $2 \mathrm{~h}$. The precipitate formed was allowed to settle for $24 \mathrm{~h}$ at room temperature and then separated, filtered, dried and powdered as described above.

Some characteristics of the adsorbents are given in Table 1. Methylene blue, $\mathrm{C}_{16} \mathrm{H}_{18} \mathrm{CIN}_{3} \mathrm{~S} \cdot 3 \mathrm{H}_{2} \mathrm{O}$ supplied by Sigma-Aldrich was used as the adsorbate.

\section{Instrumentation}

To estimate if a surface is positively or negatively charged, zeta-potential of particles of the sorbents dispersed in distilled water was measured by electrophoresis method on Zetasizer Nano ZS (Malvern Instruments).

The ability of the investigated materials to adsorb methylene blue was studied at static conditions at $25 \pm$ $2{ }^{\circ} \mathrm{C}$ using model aqueous solutions of the dye with initial concentrations from 5 to $350 \mathrm{mg} / \mathrm{L}$. $50 \mathrm{~mL}$ of the model solutions were added to $100 \mathrm{~mL}$ cone flasks containing the samples of the sorbents $0.1 \pm 0.001 \mathrm{~g}$, the mixtures were shaken thoroughly. After the process had been completed the suspensions were centrifuged with the rate $6000 \mathrm{rpm}$ for $10 \mathrm{~min}$. The residual concentration of $M B$ in the solutions was measured by spectrophotometry on SPECORD 120 PLUS (Germany) at $\lambda=663 \mathrm{~nm}$ in a $10 \mathrm{~mm}$ cuvette.

Adsorption was calculated according to the following eq. (1):

$\mathrm{q}_{\mathrm{e}}=\frac{\left(\mathrm{C}_{\mathrm{i}}-\mathrm{C}_{\mathrm{e}}\right) \mathrm{V}}{\mathrm{m}}$

where $\mathrm{q}_{\mathrm{e}}$ is mass of $\mathrm{MB}$ adsorbed on adsorbents, $\mathrm{mg} / \mathrm{g}$; $\mathrm{C}_{\mathrm{i}}, \mathrm{C}_{\mathrm{e}}$ are the initial and equilibrium concentrations of $\mathrm{MB}$ solutions respectively, $\mathrm{mg} / \mathrm{L} ; \mathrm{V}$ is the volume of the solution, $\mathrm{L} ; \mathrm{m}$ is mass of absorbent, $\mathrm{g}$.

$\mathrm{pH}$ of solutions varied from 4 to 12 by adding 0.1 $\mathrm{M} \mathrm{HCl}$ and $0.1 \mathrm{M} \mathrm{NaOH}$ solutions. $\mathrm{pH}$ was measured with the $\mathrm{pH}$ meter Multitest IPL-101 (Russian Federation). 
The effectiveness of adsorption of MB from model aqueous solutions was calculated as:

$\mathrm{H}=\frac{\mathrm{C}_{\mathrm{i}}-\mathrm{C}_{\mathrm{e}}}{\mathrm{C}_{\mathrm{i}}} 100 \%$

\section{RESULT AND DISCUSSION}

\section{pH Effect on the Effectiveness of Adsorption of MB from Model Aqueous Solutions}

$\mathrm{pH}$ value of dye solutions is essential to adsorption and influences substantially on its effectiveness because properties of the adsorbent surface depend on it. The dependence of the effectiveness of adsorption of MB from model aqueous solutions on $\mathrm{pH}$ is shown in Fig. 1.

The results demonstrate that the effectiveness of $\mathrm{MB}$ adsorption increases more significantly as $\mathrm{pH}$ raises from 8 to 12. It increases from 92 to $100 \%$ for BT6, from 7 to $38 \%$ for $\mathrm{HA}$, and from 96 to $100 \%$ for $\mathrm{C}-\mathrm{HA}$ in the $\mathrm{pH}$ range mentioned above. At lower $\mathrm{pH}$, the effectiveness of $M B$ adsorption decreases. This behavior can be explained by the reactions on the hydroxyapatite surface in aqueous media [25]. The scheme of the elementary fragment of HA surface is shown in Fig. 2. The dissociation of main groups on the surface according to the schemes $\mathrm{Ca}-\mathrm{OH}^{+} \leftrightarrow \mathrm{Ca}^{2+}+\mathrm{OH}^{-}$and $\mathrm{H}_{2} \mathrm{PO}_{4}^{-} \leftrightarrow$ $\mathrm{HPO}_{4}{ }^{2-}+\mathrm{H}^{+}$is accompanied by the release of $\mathrm{OH}^{-}$or $\mathrm{H}^{+}$ ions to the outer side of the double-electric layer, which provides a positive or negative charge of HA particles.

$\mathrm{pH}$ values of zero point of charge $\left(\mathrm{pH}_{\mathrm{pzc}}\right)$ for $\mathrm{HA}$ and $\mathrm{C}-\mathrm{HA}$ are 6.9 and 6.8 respectively. In basic media $(\mathrm{pH}>$ $\mathrm{pH}_{\mathrm{pzc}}$ ) protons split out and the surface of $\mathrm{HA}$ and $\mathrm{C}-\mathrm{HA}$ gets a negative charge that promotes adsorption of $\mathrm{MB}$ cations. The surface of both of $\mathrm{HA}$ and $\mathrm{C}-\mathrm{HA}$ is negatively charged at acidic $\mathrm{pH}\left(\mathrm{pH}<\mathrm{pH}_{\mathrm{pzc}}\right)$ mainly due to the dissociation like as $\mathrm{Ca}-\mathrm{OH}^{+} \leftrightarrow \mathrm{Ca}^{2+}+\mathrm{OH}^{-}$. As a result, the positively charged surface cannot absorb MB cations effectively because of electrostatic repulsion [14]. However, despite low $\mathrm{pH}$, electrostatic repulsion, and competitive adsorption of $\mathrm{H}^{+}$ions, a substantial amount of amount of $\mathrm{MB}$ is absorbed.

The effectiveness of $\mathrm{MB}$ adsorption in $\mathrm{pH}$ range 48 is $80-92 \%$ for BT6, $6-7 \%$ for $\mathrm{HA}$ and $91-96 \%$ for C-HA. This result can be explained by other mechanisms of $\mathrm{MB}$ adsorption on both of $\mathrm{HA}$ and C-HA. As it is reported in Ref. [14], the group $\equiv \mathrm{P}-\mathrm{OH}$ can bind with the group $\mathrm{C}=\mathrm{N}$ of $\mathrm{MB}$ molecule by hydrogen bond. Besides, the nitrogen atom of $\mathrm{MB}$ can interact with $\mathrm{Ca}^{2+}$ in $\mathrm{HA}$ through Lewis acid-base interaction. The scheme of possible processes in $\mathrm{MB}$ adsorption on HA surface is shown in Fig. 3.

At $\mathrm{pH}<\mathrm{pH}_{\mathrm{pzc}}$ the adsorption is mainly due to the mechanisms (b) and (c), whereas at $\mathrm{pH}>\mathrm{pH}_{\mathrm{pzc}}$ it goes by (a) and (b).

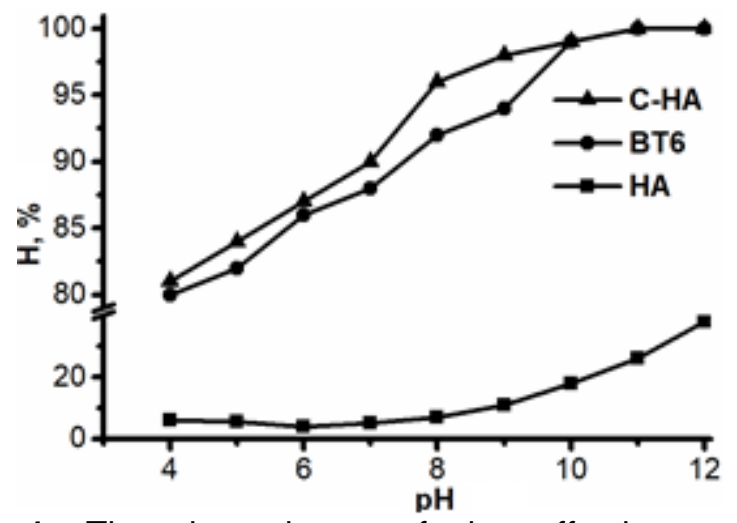

Fig 1. The dependence of the effectiveness of adsorption of $\mathrm{MB}$ from model aqueous solutions on $\mathrm{pH}$ for the adsorbents

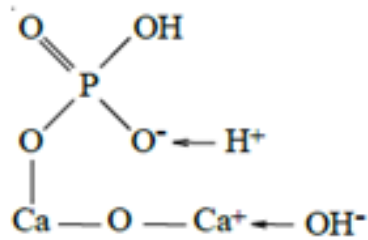

Fig 2. The scheme of the elementary fragment of $\mathrm{HA}$ surface

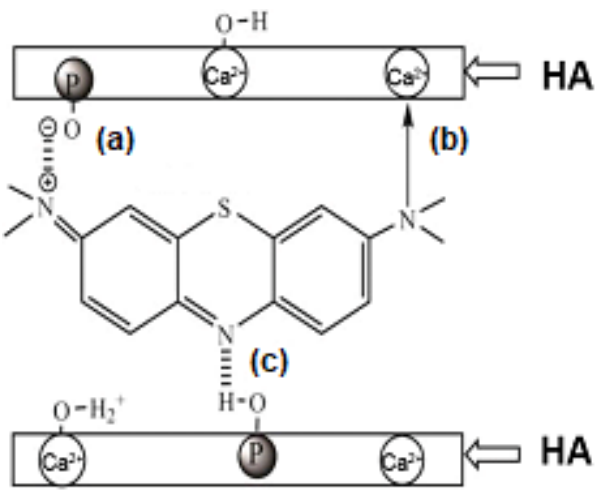

Fig 3. The mechanism of MB sorption on HA surface: (a) - Electrostatic attraction; (b) - Lewis acid-base interaction; (c) - Hydrogen bonding

The analysis of these results showed that the removal efficiency MB on the BT6 sorbent increased with increasing $\mathrm{pH}$ values and reached than $92 \%$. The removal efficiency for $\mathrm{pH}<4$ is lower due to the competition between the cations $\mathrm{MB}$ and protons $\mathrm{H}^{+}$ from the acidic medium. These can be explained: For bentonite-like clay have finely divided layered silicate can be a source of both a constant (not dependent on $\mathrm{pH}$ ) and variable surface charge (dependent on $\mathrm{pH}$ ). The constant charge is characterized mainly by threelayered and four-layered clay silicate and is associated with the manifestation of heterovalent isomorphism in 
the crystal lattice-isomorphous substitution of $\mathrm{Si}^{4+}$ to $\mathrm{Al}^{3+}$ in a tetrahedral grid and/or isomorphic substitution of $\mathrm{Al}^{3+}$ to $\mathrm{Mg}^{2+}$ in octahedral. The source of the variable charge, which is localized on the lateral cleavages of clay crystallites. Hydroxyl groups located on the lateral cleavages of clay crystallites are capable of protonationdeprotonation reactions depending on the $\mathrm{pH}$ of the surrounding solution [26].

The broken bonds and $\mathrm{M}-\mathrm{OH}$ bonds along the surfaces of the clay crystals result in hydrolysis [27].

At low $\mathrm{pH}\left(\mathrm{pH}<\mathrm{pH}_{\mathrm{pzc}}\right)$, electrostatic repulsion occurred between the MB cations and the edge groups with a positive charge $\left(\mathrm{M}-\mathrm{OH}_{2}{ }^{+}\right)$on the surface as follows: $\mathrm{MOH}+\mathrm{H}^{+} \rightarrow \mathrm{MOH}_{2}^{+}$

At high $\mathrm{pH}(\mathrm{pH}>\mathrm{pH} \mathrm{pzc})$, the surface of clay becomes negatively charged and electrostatic repulsion decreases, the MB cations in solution will be attracted to the surface according to the following reactions:

$\mathrm{MOH}+\mathrm{OH}^{-} \rightarrow \mathrm{MO}^{-}+\mathrm{H}_{2} \mathrm{O}$

where $\mathrm{M}$ is the cation of $\mathrm{Si}^{2+}, \mathrm{Al}^{3+}$ or $\mathrm{Fe}^{2+}$

There might be another mode of adsorption (ion exchange) and the results are in harmony with the literature reports [27-28].

\section{Kinetics of MB Adsorption on the Experimental Sorbents}

Adsorption kinetics is one of the most important issues that are used to estimate the effectiveness of adsorbents. The obtained kinetic curves for $\mathrm{MB}$ adsorption on the sorbents involved are given in Fig. 4. As it can be seen the adsorption equilibrium is achieved in 20-40 min.

The pseudo-first and pseudo-second-order models are widely used to describe the kinetics of adsorption on a solution-solid boundary $[11,29]$. The corresponding linearized kinetic equations are as follows:

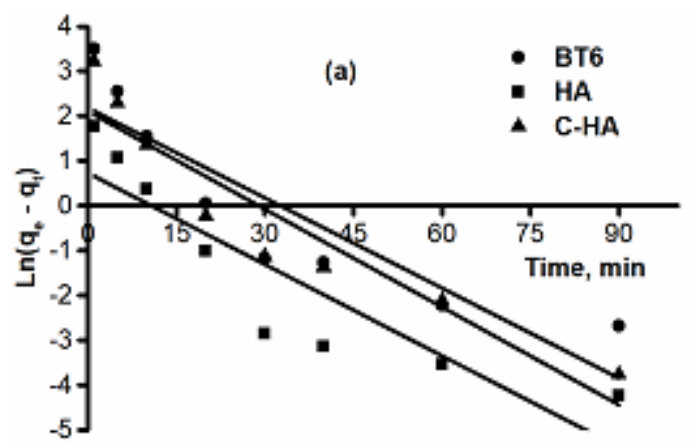

$\ln \left(q_{e}-q_{t}\right)=\ln q_{e}-k_{1} \cdot t$

$\frac{\mathrm{t}}{\mathrm{q}_{\mathrm{t}}}=\frac{1}{\mathrm{k}_{2} \cdot \mathrm{q}_{\mathrm{e}}^{2}}+\frac{1}{\mathrm{q}_{\mathrm{e}}} \cdot \mathrm{t}$

where $\mathrm{k}_{1}$ is the rate constant in the pseudo-first-order model, $\mathrm{min}^{-1} ; \mathrm{k}_{2}$ is the rate constant in the pseudosecond-order model, $\mathrm{g} \cdot \mathrm{mg}^{-1} \cdot \mathrm{min}^{-1} ; \mathrm{q}_{t}$ is mass of adsorbed $\mathrm{MB}$ on unit mass of an adsorbent at time moment $\mathrm{t}, \mathrm{mg} \cdot \mathrm{g}^{-1}$.

The dependences $\ln \left(q_{e}-q_{t}\right)=f(t)$ and $t / q_{t}=f(t)$ for $\mathrm{MB}$ adsorption process on the sorbents are shown in Fig. 5.

The pseudo-first order kinetic equations are found to describe satisfactorily the experimental data just for initial stages of the process, whereas the pseudosecond-order model is acceptable in all time interval investigated. Values of $\mathrm{k}_{1}, \mathrm{k}_{2}$, and $\mathrm{q}_{\mathrm{e}}$ calculated according to the eq. (3) and (4) are given in Table 2.

Correlation coefficients $\left(R^{2}\right)$ are better when the pseudo-second-order model is applied. Values of equilibrium concentrations $q_{e}$ calculated from the dependencies are in close agreement with experimental

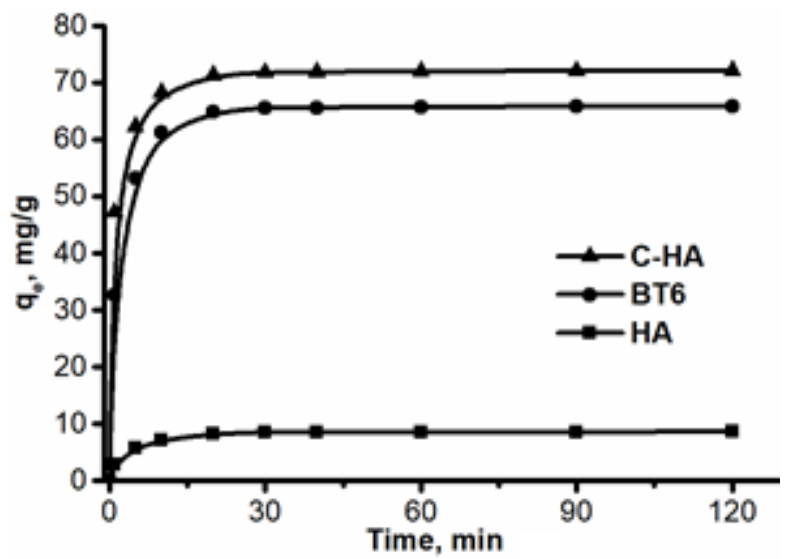

Fig 4. The kinetic curves for $M B$ adsorption on the experimental sorbents

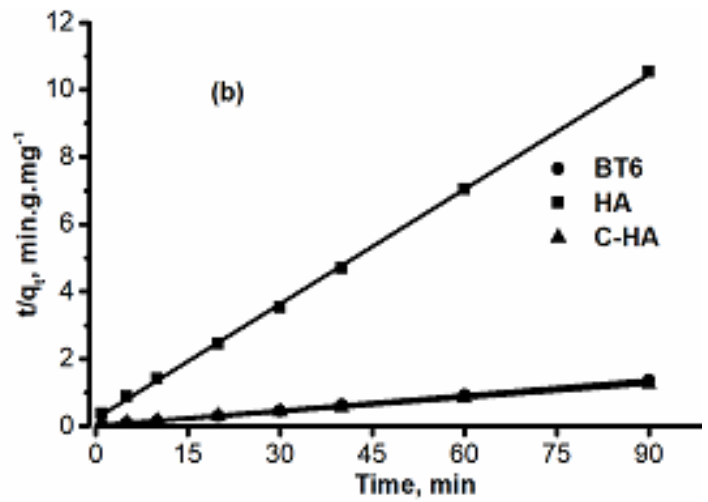

Fig 5. The kinetic dependences for MB adsorption on the experimental sorbents as a pseudo-first (a) and pseudosecond (b) order process 
Table 2. Kinetic parameters of MB adsorption on the experimental sorbents

\begin{tabular}{lccccccc}
\hline \multirow{2}{*}{ Adsorbent } & \multirow{2}{*}{$\begin{array}{c}\mathrm{q}_{\mathrm{e}} \text { experimental, } \\
\mathrm{mg} \cdot \mathrm{g}^{-1}\end{array}$} & \multicolumn{3}{c}{ pseudo-first model } & \multicolumn{3}{c}{ pseudo-second order model } \\
\cline { 3 - 8 } & & $\mathrm{min}^{-1}$ & $\begin{array}{c}\mathrm{q}_{\mathrm{e}} \\
\mathrm{mg} \cdot \mathrm{g}^{-1}\end{array}$ & $\mathrm{R}^{2}$ & $\begin{array}{c}\mathrm{k} 2 \\
\mathrm{~g} \cdot \mathrm{mg}^{-1} \cdot \mathrm{min}^{-1}\end{array}$ & $\begin{array}{c}\mathrm{q}_{\mathrm{e}} \\
\mathrm{mg} \cdot \mathrm{g}^{-1}\end{array}$ & $\mathrm{R}^{2}$ \\
\hline BT6 & 65.85 & 0.0955 & 14.73 & 0.885 & 0.0176 & 66.67 & 0.999 \\
HA & 8.57 & 0.0678 & 2.07 & 0.812 & 0.0583 & 8.81 & 0.999 \\
C-HA & 72.08 & 0.0726 & 8.16 & 0.886 & 0.0251 & 72.46 & 0.999 \\
\hline
\end{tabular}

data in this case. On the contrary, calculated and experimental values $q_{e}$ are quite different if the pseudofirst-order equation is used.

The most part of sorption processes occurs by a series of steps. These multi-step mechanisms include (i) diffusion of a sorptive through a liquid film surrounding solid particles (the process of external mass transport), (ii) diffusion inside the particles (intraparticle diffusion), and (iii) a physical or chemical adsorption [30].

First, to describe the mechanism of $\mathrm{MB}$ adsorption on the investigated sorbents and to determine its limiting stage we used Weber and Morris model [31], which is applicable to intraparticle diffusion. According to the model, $\mathrm{q}_{\mathrm{t}}$ depends on time as

$\mathrm{q}_{\mathrm{t}}=\mathrm{k}_{\mathrm{i}}\left(\mathrm{t}^{1 / 2}\right)$

where $k_{i}$ - the rate constant for intraparticle diffusion, $\left(\mathrm{mg} / \mathrm{g} \min ^{1 / 2}\right)$.

The dependences of adsorption $\mathrm{q}_{\mathrm{t}}$ on $\mathrm{t}^{1 / 2}$ calculated from experimental data are given in Fig. 6. A linear approximation of the experimental data for all three sorbents gives two straight-lined segments which point to two stages of MB diffusion to the sorbents. Here the kinetic parameters corresponding to intraparticle diffusion are characterized by the slope of the second segment. The $Y$-intercept is proportional to the thickness of the film surrounding the particles of the sorbents [30-31].

To determine the limiting stage of the sorption process the equation given by Boyd $[29,31]$ was used

$\mathrm{F}=1-\left(6 / \pi^{2}\right) \exp (-\mathrm{Bt})$

where $F$ is the fraction of solute adsorbed at different times $t$, and $B t$ is a mathematical function of $F$, which are given by the following relationships

$$
\begin{aligned}
& \mathrm{F}=\mathrm{q}_{\mathrm{t}} / \mathrm{q}_{\mathrm{e}} \\
& \mathrm{Bt}=-0.4977-\ln \left(1-\mathrm{q}_{\mathrm{t}} / \mathrm{q}_{\mathrm{e}}\right)
\end{aligned}
$$

Using experimental data for $q_{t}$ and $q_{e}$ we calculated Bt. The linear dependence of Bt on $\mathrm{t}$ (Fig. 7) is considered to argue for interdiffusion limiting [31].

Our dependences are linear for all investigated sorbents but they do not pass through the origin. This means that the external mass transfer seems to control the process of sorption [29,31].

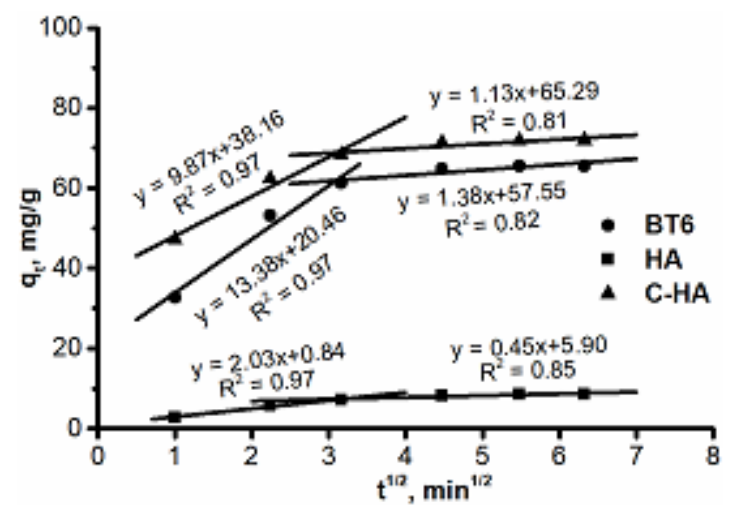

Fig 6. The experimental dependences of $q_{t}$ on $t^{1 / 2}$ for the experimental sorbents

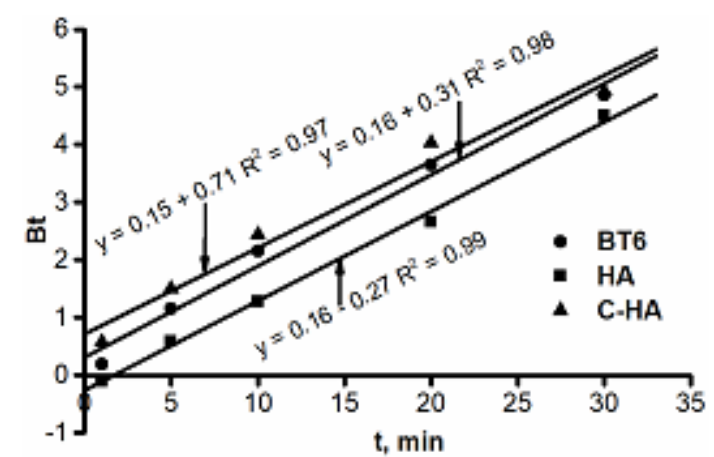

Fig 7. The dependence of Bt on $t$

\section{Adsorption Isotherms}

To interpret experimental data the linearized Langmuir and Freundlich equations were used

$\frac{C_{e}}{q_{e}}=\frac{C_{e}}{q_{m}}+\frac{1}{q_{m} \cdot K_{L}}$

$\ln \mathrm{q}_{\mathrm{e}}=\ln \mathrm{K}_{\mathrm{F}}+\frac{1}{\mathrm{n}} \ln \mathrm{C}_{\mathrm{e}}$

where $q_{m}$ is the maximal adsorption (adsorption capacity) mg/g; $\mathrm{K}_{\mathrm{L}}$ Langmuir constant, L/mg; $\mathrm{K}_{\mathrm{F}}, \mathrm{n}$ are constants in Freundlich sorption isotherm.

The experimental adsorption isotherms at $298 \mathrm{~K}$, $\mathrm{pH}=8-9$, and the dependences linearized according to both of Langmuir and Freundlich equations are shown in Fig. 8. 

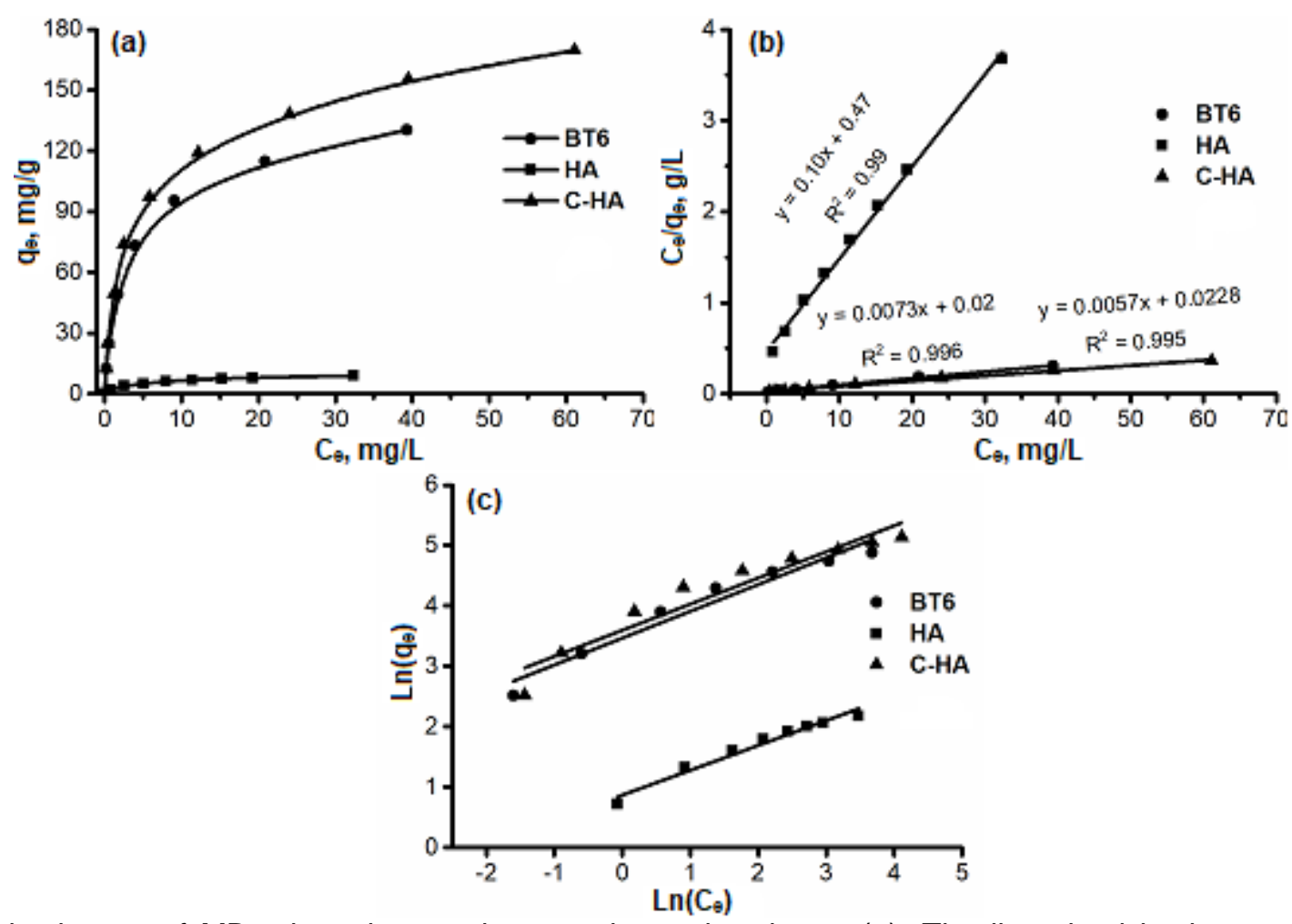

Fig 8. The isotherms of MB adsorption on the experimental sorbents (a). The linearized isotherms according to Langmuir (b) and Freundlich (c) equations

Table 3. Parameters of Langmuir and Freundlich equations for MB adsorption isotherms on the investigated sorbents

\begin{tabular}{lccccccc}
\hline \multirow{2}{*}{ Sorbent } & $\mathrm{T},(\mathrm{K})$ & \multicolumn{3}{c}{ Pangmuir } & \multicolumn{3}{c}{ Freundlich } \\
\cline { 3 - 8 } & & $\mathrm{q}, \mathrm{mg} / \mathrm{g}$ & $\mathrm{K}_{\mathrm{L}, \mathrm{L} / \mathrm{mg}}$ & $\mathrm{R}^{2}$ & $\mathrm{~K}_{\mathrm{F}}$ & $\mathrm{n}$ & $\mathrm{R}^{2}$ \\
\hline BT6 & 298 & 136.98 & 0.323 & 0.996 & 31.928 & 2.255 & 0.955 \\
& 313 & 138.89 & 0.391 & 0.994 & 35.769 & 2.377 & 0.961 \\
& 333 & 140.85 & 0.483 & 0.992 & 39.721 & 2.395 & 0.956 \\
\hline HA & 298 & 9.88 & 0.216 & 0.996 & 2.380 & 2.433 & 0.970 \\
& 313 & 10.67 & 0.213 & 0.992 & 2.559 & 2.427 & 0.979 \\
& 333 & 11.21 & 0.229 & 0.989 & 2.808 & 2.480 & 0.985 \\
\hline C-HA & 298 & 175.44 & 0.252 & 0.995 & 36.98 & 2.322 & 0.946 \\
& 313 & 181.82 & 0.314 & 0.992 & 41.89 & 2.321 & 0.950 \\
& 333 & 185.19 & 0.422 & 0.991 & 49.01 & 2.392 & 0.954 \\
\hline
\end{tabular}

Adsorption ability of the sorbents can be seen to increase in the same consequence like as the rate of $\mathrm{MB}$ adsorption HA < BT6 < C-HA. The maximal adsorption (adsorption capacity) for the composite sorbent C-HA is $175.4 \mathrm{mg} / \mathrm{g}$ at $298 \mathrm{~K}$ which is 1.28 times more than that for bentonite-like clay, and 17.8 times more than that for HA. This behavior can be explained: The adsorption of $M B$ is primarily influenced by the surface charge on the adsorbent [32] (Zeta-potential of BT6 $=-25 \mathrm{mV}$; HA $=+$ $2 \mathrm{mV}$; C-HA $=-22 \mathrm{mV}$ ). In addition, methylene blue can be adsorbed both on the surface of montmorillonite and in the interlayer space (ion exchange). The large specific surface area of $\mathrm{C}$-HA promotes an increase in the adsorption of the dye (Specific surface area of BT6 =
52.11; $\mathrm{HA}=85.78 ; \mathrm{C}-\mathrm{HA}=96.81 \mathrm{~m}^{2} / \mathrm{g}$ ). Parameters of both Langmuir and Freundlich equations calculated from the linearized isotherms are given in Table 3.

Data from Table 3 and Fig. 8 (b, c) demonstrate that Langmuir equation seems to be a bit more preferable to describe adsorption of MB on bentonitelike clay BT6, hydroxyapatite $\mathrm{HA}$, and composite sorbent $\mathrm{C}-\mathrm{HA}\left(\mathrm{R}^{2}>0.99\right)$.

\section{Thermodynamics of MB Adsorption on the Sorbents}

To describe thermodynamics of MB adsorption the isotherms at three values of temperature, namely 298, 313 , and $333 \mathrm{~K}$, were obtained $(\mathrm{pH}=10.0)$. The constant 

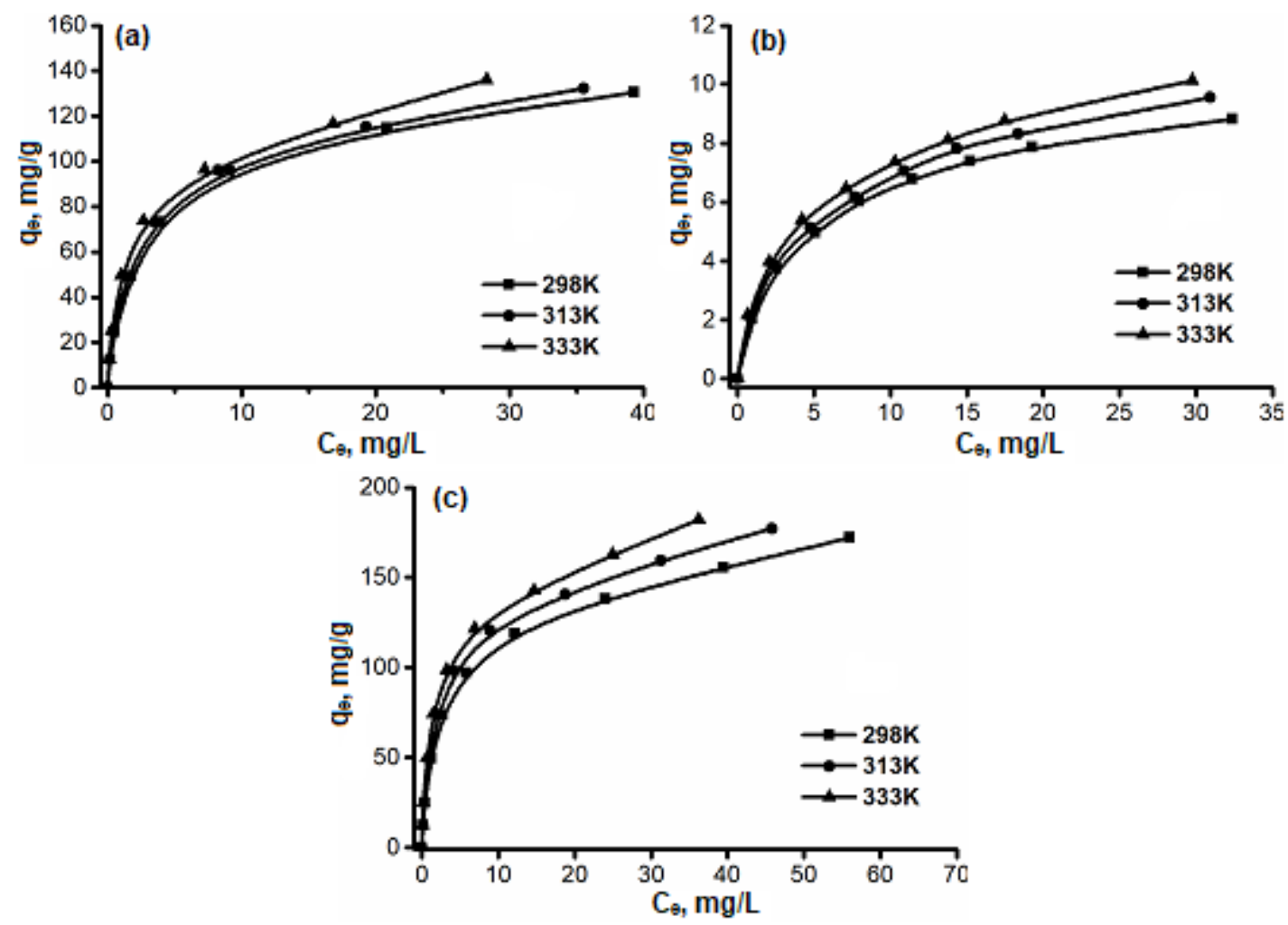

Fig 9. MB adsorption isotherms at three temperatures on the experimental sorbents: (a) BT6, (b) HA, (c) C-HA

Table 4. Thermodynamic functions for MB adsorption on the investigated sorbents

\begin{tabular}{lcccc}
\hline Sorbent & $\begin{array}{c}\mathrm{T} \\
(\mathrm{K})\end{array}$ & $\begin{array}{c}\Delta \mathrm{G}^{0} \\
\mathrm{~kJ} / \mathrm{mol}\end{array}$ & $\begin{array}{c}\Delta \mathrm{H}^{0} \\
\mathrm{~kJ} / \mathrm{mol}\end{array}$ & $\begin{array}{c}\Delta \mathrm{S}^{0} \\
\mathrm{~J} / \mathrm{mol} \cdot \mathrm{K}\end{array}$ \\
\hline \multirow{2}{*}{ BT6 } & 298 & -38.56 & & \\
& 313 & -40.98 & 9.47 & 161.2 \\
& 333 & -44.21 & & \\
$\mathrm{H}$ & 298 & -37.52 & & \\
& 313 & -39.48 & 1.43 & 130.7 \\
& 333 & -42.09 & & \\
C-HA & 298 & -37.93 & & \\
& 313 & -40.45 & 12.17 & 168.1 \\
\hline
\end{tabular}

of adsorption equilibrium and its dependence on temperature make it possible to estimate Gibbs free energy change, enthalpy, and entropy for the process.

The standard Gibbs free energy change was calculated as follows:

$\Delta \mathrm{G}^{0}=-\mathrm{RT} \ln \mathrm{K}^{0}$

where $\mathrm{R}$ is gas constant, $\mathrm{T}$ is absolute temperature, $\mathrm{K}^{0}$ is the constant of adsorption equilibrium (dimensionless). Values $\mathrm{K}^{0}$ can be found using Langmuir constants $\mathrm{K}_{\mathrm{L}}$ according to the relationship [33]:

$\mathrm{K}^{0}=\mathrm{K}_{\mathrm{L}}(\mathrm{L} / \mathrm{mg}) \times 1000 \times \mathrm{M}_{\mathrm{MB}}(\mathrm{g} / \mathrm{mol}) \times 55.5$

$M_{M B}=319.85(\mathrm{~g} / \mathrm{mol})$ is the molar mass of $M B$.

Temperature dependence of the equilibrium constant can be written as $\ln K^{0}=-\frac{\Delta H^{0}}{R T}+\frac{\Delta S^{0}}{R}$

The experimental isotherms of MB adsorption at different temperatures are shown in Fig. 9. Values of enthalpy $\Delta \mathrm{H}^{0}$ and entropy $\Delta \mathrm{S}^{0}$ were found from the slope and intercept of linear dependence of $\ln \mathrm{K}^{0}$ on reciprocal temperature (Fig. 10). The results are given in Table 4. As it can be seen the enthalpy changes $\Delta \mathrm{H}^{0}$ are slightly positive in the temperature range investigated that argues for the endothermic character of the process. Values of standard Gibbs free energy change $\Delta G^{0}$ are negative and they decrease in the range of temperature 298-333 K. They point out the spontaneity of MB adsorption on the adsorbent involved and the values are 


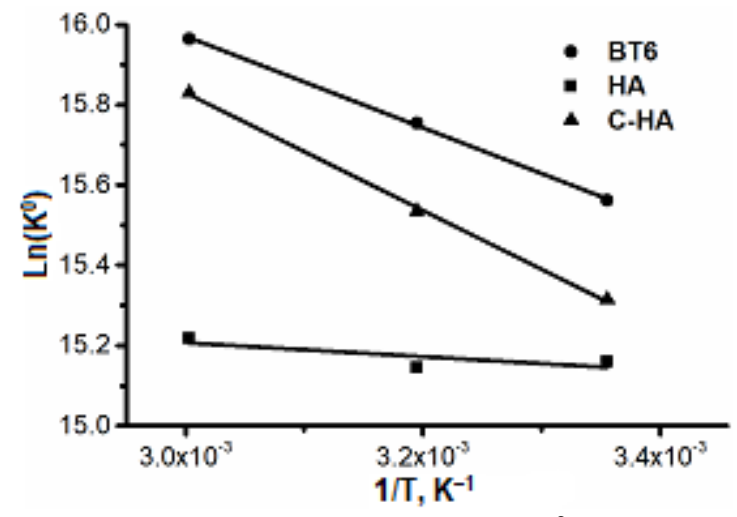

Fig 10. The dependences of $\mathrm{In} \mathrm{K}^{0}$ on reciprocal temperature for $\mathrm{MB}$ adsorption on the experimental sorbents

consistent with other results [34]. The process becomes a bit more preferable as the temperature rises. Positive entropy changes $\Delta S^{0}$ correspond to the increase of freedom in the system because of MB adsorption. Entropy increase can be explained by the release of hydrated inorganic cations from adsorbents and structural changes as a result of $\mathrm{MB}$ molecules interaction with an active group on the surfaces of adsorbents [35].

\section{CONCLUSION}

The results of the investigation have shown that adsorption of methylene blue on the adsorbents involved obeys Langmuir isotherm equation. It is spontaneous but slightly endothermic. The maximal sorption capacity of the composite sorbent is found to be equal $175.4 \mathrm{mg} / \mathrm{g}$ at $25^{\circ} \mathrm{C}$ that is 1.3 times higher than that for bentonite-like clay and 17.8 times higher than that for hydroxyapatite. Kinetics of the process is due to the combination of external and internal diffusion and can be described better by the model of pseudo-second order reaction. The results can be useful in the development of adsorption technology of natural and wastewater purification from methylene blue and other organic cationic dyes using the composite sorbent based on bentonite-like clay and hydroxyapatite.

\section{REFERENCES}

[1] Zhang, F., Zhao, Z., Tan, R., Guo, Y., Cao, L., Chen, L., Li, J., Xu, W., Yang, Y., and Song, W., 2012, Selective and effective adsorption of methyl blue by barium phosphate nano-flake, J. Colloid Interface Sci., 386 (1), 277-284.

[2] Hao, O.J., Kim, H., and Chiang, P.C., 2000, Decolorization of wastewater, Crit. Rev. Environ. Sci. Technol., 30 (4), 449-505.

[3] Gupta, N., Kushwaha, A.K., and Chattopadhyaya,
M.C., 2012, Adsorption studies of cationic dyes onto Ashoka (Saraca asoca) leaf powder, J. Taiwan Inst. Chem. Eng., 43 (4), 604-613.

[4] Brown, M.A., and DeVito, S.C., 1993, Predicting azo dye toxicity, Crit. Rev. Environ. Sci. Technol., 23 (3), 249-324.

[5] Kapdan, I.K., and Kargi, F., 2002, Simultaneous biodegradation and adsorption of textile dyestuff in an activated sludge unit, Process Biochem., 37 (9), 973-981.

[6] Prasad, R.K., 2009, Color removal from distillery spent wash through coagulation using Moringa oleifera seeds: Use of optimum response surface methodology, J. Hazard. Mater., 165 (1-3), 804811.

[7] Solozhenko, E.G., Soboleva, N.M., and Goncharuk, V. V., 1995, Decolourization of azodye solutions by Fenton's oxidation, Water Res., 29 (9), 2206-2210.

[8] Buckley, C.A., 1992, Membrane technology for the treatment of dyehouse effluents, Water Sci. Technol., 25 (10), 203-209.

[9] Panizza, M., Barbucci, A., Ricotti, R., and Cerisola, G., 2007, Electrochemical degradation of methylene blue, Sep. Purif. Technol., 54 (3), 382387.

[10] Ngapa, Y.D., Sugiarti, S., and Abidin, Z., 2016, Hydrothermal transformation of natural zeolite from Ende-NTT and its application as adsorbent of cationic dye, Indones. J. Chem., 16 (2), 138-143.

[11] Zhang, J., Ping, Q., Niu, M., Shi, H., and Li, N., 2013, Kinetics and equilibrium studies from the methylene blue adsorption on diatomite treated with sodium hydroxide, Appl. Clay Sci., 83-84, 12-16.

[12] Akar, T., Anilan, B., Gorgulu, A., and Akar, S.T., 2009, Assessment of cationic dye biosorption characteristics of untreated and non-conventional biomass: Pyracantha coccinea berries, J. Hazard. Mater., 168 (2-3), 1302-1309.

[13] Ciobanu, G., Ilisei, S., Harja, M., and Luca, C., 2013, Removal of Reactive Blue 204 dye from aqueous solutions by adsorption onto nanohydroxyapatite, Sci. Adv. Mater., 5 (8), 10901096.

[14] Wei, W., Yang, L., Zhong, W.H., Li, S.Y., Cui, J., and Wei, Z.G., 2015, Fast removal of methylene blue from aqueous solution by adsorption onto poorly crystalline hydroxyapatite nanoparticles, Dig. J. Nanomater. Biostruct., 10 (4), 1343-1363.

[15] Muzakky, and Supriyanto, C., 2016, Modification of three types of bentonite with zirconium oxide chloride $(\mathrm{ZOC})$ of local products using intercalation process, Indones. J. Chem., 16 (1), 14-19.

[16] Scheckel, K.G., Diamond, G.L., Burgess, M.F., Klotzbach, J.M., Maddaloni, M., Miller, B.W., Partridge, C.R., and Serda, S.M., 2013, Amending 
soils with phosphate as means to mitigate soil lead hazard: A critical review of the state of the science, J. Toxicol. Environ. Health Part B, 16 (6), 337-380.

[17] Sunarso, Sutarno, Tsuru, K., Ana, I.D., and Ishikawa, K., 2011, Effect of crosslinking to the mechanical property of apatite gelatin hybrid for bone substitution purposes, Indones. J. Chem., 11 (3), 267-272.

[18] Wang, Y., Chen, N., Wei, W., Cui, J., and Wei, Z., 2011, Enhanced adsorption of fluoride from aqueous solution onto nanosized hydroxyapatite by lowmolecular-weight organic acids, Desalination., 276 (1-3), 161-168.

[19] Dong, L., Zhu, Z., Qiu, Y., and Zhao, J., 2010, Removal of lead from aqueous solution by hydroxyapatite/magnetite composite adsorbent, Chem. Eng. J., 165 (3), 827-834.

[20] Jang, S.H., Jeong, Y.G., Min, B.G., Lyoo, W.S., and Lee, S.C., 2008, Preparation and lead ion removal property of hydroxyapatite/polyacrylamide composite hydrogels, J. Hazard. Mater., 159 (2-3), 294-299.

[21] Jang, S.H., Min, B.G., Jeong, Y.G., Lyoo, W.S., and Lee, S.C., 2008, Removal of lead ions in aqueous solution by hydroxyapatite/polyurethane composite foams, J. Hazard. Mater., 152 (3), 1285-1292.

[22] Hou, H., Zhou, R., Wu, P., and Wu, L., 2012, Removal of Congo red dye from aqueous solution with hydroxyapatite/chitosan composite, Chem. Eng. J., 212-213, 336-342.

[23] Choi, S., and Jeong, Y., 2008, The removal of heavy metals in aqueous solution by hydroxyapatite/ cellulose composite, Fibers Polym., 9 (3), 267-270.

[24] Vezentsev, A.I., Peristaya, F.L., Glukhareva, N.A., and Thuy, D.M., 2018, A composite sorbent based on bentonite-like clay and hydroxyapatite, J. Fundam. Appl. Sci., 10 (4S), 1099-1111.

[25] Tarasevich, Y.I., Shkutkova, E.V., and Janusz, W., 2012, Sorption of ions of heavy metals from aqueous solutions on hydroxylapatite, J. Water Chem. Technol., 34 (3), 125-132.

[26] Sokolova, T.A., and Trofimov, S.Ya., 2009, Sorption
Properties of Soils. Adsorption. Cation Exchange, eds., Chukov, S.N., and Pinski, D.L., Tula, Moskva, 172.

[27] Tahir, S.S., and Rauf, N., 2006, Removal of a cationic dye from aqueous solutions by adsorption onto bentonite clay, Chemosphere, 63 (11), 18421848.

[28] Weng, C.H., and Pan, Y.F., 2007, Adsorption of a cationic dye (methylene blue) onto spent activated clay, J. Hazard. Mater., 144 (1-2), 355-362.

[29] Kumar, K.V., Ramamurthi, V., and Sivanesan, S., 2005, Modeling the mechanism involved during the sorption of methylene blue onto fly ash, J. Colloid Interface Sci., 284 (1), 14-21.

[30] Porkodi, K., and Kumar, V., 2007, Equilibrium, kinetics and mechanism modeling and simulation of basic and acid dyes sorption onto jute fiber carbon: Eosin yellow, malachite green and crystal violet single component systems, J. Hazard. Mater., 143 (1-2), 311-327.

[31] Wang, S., and Li, H., 2007, Kinetic modelling and mechanism of dye adsorption on unburned carbon, Dyes Pigm., 72, 308-314.

[32] Chandrasekhar, S., and Pramada, P.N., 2006, Rice husk ash as an adsorbent for methylene blue-effect of ashing temperature, Adsorption, 12, 27-43.

[33] Zhou, X., and Zhou, X., 2014, The unit problem in the thermodynamic calculation of adsorption using the Langmuir equation, Chem. Eng. Commun., 201 (11), 1459-1467.

[34] Hong, S., Wen, C., He, J., Gan, F., and Ho, Y.S., 2009, Adsorption thermodynamics of Methylene Blue onto bentonite, J. Hazard. Mater., 167 (1-3), 630-633.

[35] Almeida, C.A.P., Debacher, N.A., Downs, A.J., Cottet, L., and Mello, C.A.D., 2009, Removal of methylene blue from colored effluents by adsorption on montmorillonite clay, J. Colloid Interface Sci., 332 (1), 46-53. 